\title{
ANALISIS SISTEM ANTRIAN PADA PEGADAIAN SYARIAH KANTOR CABANG LANGSA
}

\author{
W. Tamara1, Nurviana² dan Amelia $^{3}$
}

\author{
1,2,3Program Studi Matematika, Fakultas Teknik, Universitas Samudra \\ 1wulan.tamara123@gmail.com, 2nurviana@unsam.ac.id, 3ameliamath@unsam.ac.id
}

\begin{abstract}
The queuing process is a process related to the arrival of customers at a service facility, waiting in a queue line if they have not received service, and finally leaving the service facility after receiving service. Queuing is a phenomenon that often occurs in everyday life and is often encountered in public service facilities. The high flow of customer get tired of waiting. This research was conducted at the Pegadaian Syariah Langsa Branch Office. The purpose of this study is to see the average service time, to determine the performance of the queuing system, and to analyze the applied queuing model. The queuing structure model used at Pegadaian Syariah Langsa Branch Office is Single Channel - Single Phase and Single Channel - Multi Phase with the characteristics of First In First Out (FIFO). To determine the queuing modeling, data on arrival time and service time are needed at the Pegadaian Syariah Langsa Branch Office. In the analysis of the Single Channel - Single Phase queuing structure, the model obtained at Pegadaian Syariah Langsa Branch Office is (M/G/1);(FIFO/布) with the longest time for customers has to wait in the queue $\left(\mathrm{W}_{\mathrm{q}}\right)$ which is 5 minutes and the queue structure of the Single Channel Multi Phase model obtained at Pegadaian Syariah Langsa Branch Office is (M/G/2) );(FIFO/ / $/ \infty)$ the longest time a customers has to wait in the queue $\left(\mathrm{W}_{\mathrm{q}}\right)$ is 8 minutes on the first service, 27 minutes for the second service.
\end{abstract}

Keywords : : Queue Theory, Single Channel - Single Phase, Single Channel - Multi Phase,

(M/G/1);(FIFO/ / $/ \infty),(M / G / 2) ;(F I F O / \infty / \infty)$

\section{ABSTRAK}

Proses antrian merupakan suatu prosesyang berhubungan dengan kedatangan pelanggan pada suatu fasilitas pelayanan, menunggu dalam baris antrian apabila belum mendapat pelayanan, dan akhirnya meninggalkan fasilitas pelayanan tersebut sesudah mendapatkan pelayanan. Mengantri merupakan salah satu fenomena yang sering terjadi dalam kehidupan sehari-hari dan sering kita temui dalam fasilitas-fasilitas pelayanan umum. Tingginya arus kedatangan nasabah pada waktu-waktu tertentu mengakibatkan antrian yang panjang dan lama sehingga nasabah bosan menunggu. Penelitian ini dilakukan pada Pegadaian Syariah Kantor Cabang Langsa. Adapun tujuan dari penelitian ini adalah untuk melihat rata-rata waktu pelayanan, untuk mengetahui kinerja sistem antrian, dan untuk menganalisis model antrian yang diterapkan. Model struktur antrian yang digunakan pada Pegadaian Syariah Kantor Cabang Langsa adalah Single Channel - Single Phase dan Single Channel - Multi Phase dengan karakteristik antrian First In First Out (FIFO). Untuk menentukan pemodelan antrian maka diperlukan data waktu kedatanagan dan waktu pelayanan pada Pegadaian Syariah Kantor Cabang Langsa. Pada hasil analisis struktur antrian Single Channel Single Phase model yang diperoleh di Pegadaian Syariah Kantor Cabang Langsa 


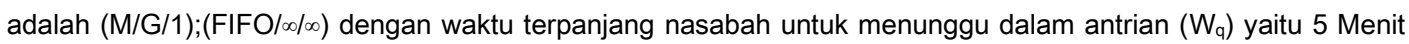
dan struktur antrian Single Channel Multi Phase model yang diperoleh di Pegadaian Syraiah Kantor Cabang

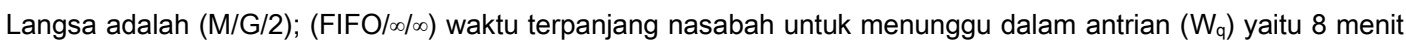
pada pelayanan pertama, 27 menit pada pelayanan kedua.

Kata kunci : Teori Antrian, Single Channel - Single Phase, Single Channel - Multi Phase, (M/G/1);(FIFO/o/ ), (M/G/2);(FIFO/ $/ \infty)$

\section{PENDAHULUAN}

Proses antrian merupakan suatu proses yang berhubungan dengan kedatangan pelanggan pada suatu fasilitas pelayanan, menunggu dalam baris antrian apabila belum mendapat pelayanan, dan akhirnya meninggalkan fasilitas pelayanan tersebut sesudah mendapatkan pelayanan (Saumi dkk, 2018). Teori antrian adalah teori yang menyangkut studi matematika dan baris - baris penungguan, mempelajari mengenai antrian yang di dalamnya disediakan beberapa alternatif model matematika yang dapat digunakan untuk menentukan beberapa karakteristik dan optimasi dalam pengambilan keputusan suatu sistem antrian (Faisal, 2005). Antrian juga merupakan kegiatan yang sering timbul dalam aktivitas manusia yang diakibatkan oleh fasilitas pelayanan yang tidak seimbang. Mengantri merupakan salah satu fenomena yang sering terjadi dalam kehidupan sehari-hari dan sering kita temui dalam fasilitas-fasilitas pelayanan umum. Tingginya arus kedatangan nasabah pada waktu-waktu tertentu, menyebabkan antrian yang panjang dan lama sehingga nasabah bosan menunggu (Amalia, 2018).

Pegadaian merupakan salah satu BUMN yang melayani jasa gadai untuk memenuhi kebutuhan keuangan. Pada sekarang ini pegadaian masih menjadi salah satu alternatif masyarakat untuk mendapatkan dana segar dengan cara menggadaikan barang berharga yang dimilikinya. Di indonesia saat ini, ada dua tipe lembaga gadai yaitu pegadaian konvensional dan pegadaian syariah. Tahun 1746, Pegadaian dimulai saat VOC mendirian Bank Van Leening sebagai lembaga keuangan yang memberikan kredit dengan sistem gadai. Tahun 1811, pemerintah inggris mengambil alih dan membubarkan Bank Van Leening, masyarakat di beri keleluasaan mendirikan usaha pergadaian. Tahun 1901, didirikan Pegadaian negara pertama di Sukabumi (Jawa Barat) Pada Tanggal 1 April 1901).Tahun 1905, pegadaian berbentuk lembaga remi “JAWATAN" 1905. Tahun 1961, bentuk badan hukum berubah "JAWATAN" ke "PN" berdasarkan Peraturan Pemerintah Pengganti Undang - undang (Perpu) No. 19 Tahun 1960 Jo Peraturan Pemerintah (PP) No. 178 Tahun 1961. Tahun 1969, bentuk badan hukum berubah dari "PN" ke "PERJAN" berdasarkan Peraturan Pemerintah (PP) No. 7 Tahun 1969. Tahun 1990, bentuk badan hukum berubah dari "PERJAN" ke "PERUM" berdasarkan Peraturan Pemerintah (PP) No. 10 Tahun 1990 yang diperbarui dengan Peraturan Pemerintah (PP) No. 103 Tahun 2000. Selanjutnya pada Tahun 2012, bentuk badan hukum berubah dari "PERUM" ke "PERSERO” Pada tanggal 1 April 2012 berdasarkan Peraturan Pemerintah (PP) No. 51 Tahun 2011. 
Teori antrian merupakan teori yang berkaitan dengan studi matematis mengenai antrian dari nasabah dan baris-baris penunggu yang memerlukan fasilitas layanan (Indrianto, 2008). Antrian merupakan suatu proses yang berkaitan dengan suatu kedatangan seseorang pada suatu fasilitas pelayanan, kemudian menunggu dalam suatu antrian pada akhirnya meningggalkan fasilitas tersebut (Aminah, 2015). Proses kedatangan terjadi jika seseorang pelanggan memasuki fasilitas pelayanan, sedangkan proses selesai pelayanan terjadi jika seseorang sudah meninggalkan fasilitas pelayanan tersebut (Purba, 2018). Dalam sistem antrian terdapat beberapa karakteristik sistem antrian, yaitu: pola kedatangan, pola antrian, distribusi pelayanan, dan mekanisme pelayanan. Pada pola kedatangan menggambarkan suatu bentuk dan ukuran kedatangan nasabah pada fasilitas pelayanan yang kedatangannya mungkin saja tidak merata. Sebuah pola acak sering digambarkan sebagai sesuatu yang tidak bisa di prediksi. Berdasarkan tingkat kedatangan rata-rata maka akan kita ketahui waktu antar kedatangan nasabah. Sistem antrian yang digunakan pada Pegadaian Syariah Cabang Langsa yaitu dengan menggunakan sistem antrian Single Channel - Single Phase artinya hanya ada satu fasilitas pelayanan yang melayani jalur tunggal dan juga menggunakan sistem antrian Single Channel - Multi Phase artinya terdapat dua atau lebih fasilitas pelayanan yang bekerja secara berurut dengan diikuti antrian tunggal.

\section{METODE PENELITIAN}

Sumber data yang digunakan dalam penelitian ini yaitu data primer. Dimana data primer merupakan hasil pengamatan dan pencatatan secara langsung dilapangan. Jenis data yang digunakan pada penelitian ini yaitu, data kuantitatif. Data yang diperoleh selama penelitian berlangsung berupa angka - angka ataupun bilangan yang mengenai jumlah kedatangan nasabah dalam mengantri dan jumlah waktu yang dihabiskan oleh nasabah dalam melakukan proses transaksi.

Data yang digunakan pada penelitian ini yaitu data yang diperoleh secara langsung dari pengamatan pada Pegadaian Syariah Kantor Cabang Langsa. Pengamatan dilakukkan selama 1 bulan mulai dari jam 09.00 - 12.00 WIB, setiap hari pada saat hari kerja. Pemilihan data dikelompokkan berdasarkan waktu kedatangan, waktu pelayanan, dan waktu selesai pelayanan (keluar). Pencatatan waktu kedatangan nasabah dilakukan dengan interval waktu 1 jam. Metode penelitian yang digunakan yaitu metode studi lapangan.

Teknik analisis data pada langkah pertama dilakukan pengumpulan data yaitu data banyaknya kedatangan dan data waktu pelayanan, setelah mendapatkan data maka akan kita uji kesesuaian yang dilakukan dengan menggunakan uji Goodness Of Fit untuk mengetahui apakah jumlah kedatangan nasabah berdistribusi Poisson, Eksponential, atau berdistribusi lainnya. langkah selanjutnya penentuan model antrian, analisis hasil penelitian dimana ketika hasil pada model antrian diperoleh sudah efektif maka pengujian selesai dan apabila hasil model antrian diperoleh belum efektif maka kita dapat merekomendasikan model yang lain. 
Pada model antrian Single Channel Single Phase merupakan model antrian dengan waktu pelayanan yang sudah efektif. Untuk rata-rata waktu pelayanan pada pegadaian syariah kantor cabang langsa model antrian Single Channe/ Single Phase adalah 5 menit, rata-rata waktu yang dihabiskan nasabah untuk menunggu dalam antrian $\left(\mathrm{W}_{\mathrm{q}}\right)$ adalah 5 menit, dan untuk waktu rata-rata yang dihabiskan nasabah dalam sistem $\left(\mathrm{W}_{\mathrm{s}}\right)$ adalah 10 Menit. Sedangkan model antrian Single Channel Multi Phase merupakan mdoel antrian dengan waktu pelayanan yang belum efektif. Untuk rata-rata waktu pelayanan pada pegadaian syariah kantor cabang langsa model antrian Single Channel Multi Phase adalah 5 menit pada pelayanan pertama dan 6 meint pada pelayanan kedua, rata-rata waktu yang dihabiskan nasabah untuk menunggu dalam antrian $\left(\mathrm{W}_{\mathrm{q}}\right)$ adalah 7,5 menit pada pelayanan pertama dan 27 menit pada pelayanan kedua, untuk waktu rata-rata yang dihabiskan nasabah dalam sistem ( $\mathrm{W}_{\mathrm{s}}$ ) adalah 12,5 Menit pada pelayanan kedua dan 33 menit pada pelayanan kedua.

\section{HASIL DAN PEMBAHASAN}

Kinerja sistem antrian Pegadaian Syariah Kantor Cabang Langsa menggunakan dua model antrian yaitu Single Channel - Single Phase artinya terdapat satu fasilitas pelayanan dengan antrian tunggal dan Single Channel - Multi Phase yang artinya terdapat dua atau lebih pelayanan yang dilaksanakan secara berurutan (dalam Phase - Phase). Disiplin antrian yang diterapkan pada Pegadaian Syariah Kantor Cabang Langsa adalah First In First Out artinya dimana pelanggan yang terlebih dahulu masuk kedalam baris antrian maka akan lebih dahulu keluar.

\subsection{Gambar dan Tabel}

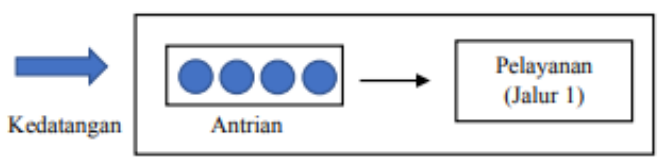

Nasabah Keluar

Gambar 1 : Sistem Antrian Pada Pegadaian Syariah Cabang Langsa Model Antrian Single Channel Single Phase

Gambar 1 di atas menjelaskan bahwa sistem antrian Single Channel Single Phase yaitu terdapat satu fasilitas pelayanan dengan antrian tunggal.

Tabel 1 : Data Rata-Rata Tingkat Kedatangan Nasabah Pegadaian Syariah Kantor Cabang Langsa Model Antrian Single Channel - Single Phase

\begin{tabular}{|c|c|c|}
\hline $\begin{array}{c}\text { Interval Waktu } \\
\text { Kedatangan (Jam) }\end{array}$ & $\begin{array}{c}\text { Jumlah Kedatangan } \\
\text { Selama 25 Hari }\end{array}$ & $\begin{array}{c}\text { Rata - Rata } \\
\text { Kedatangan }\end{array}$ \\
\hline $09.00-10.00$ & 205 & 8 Orang \\
\hline $10.00-11.00$ & 197 & 8 Orang \\
\hline $11.00-12.00$ & 182 & 7 Orang \\
\hline
\end{tabular}


Tabel 2 : Data Rata-Rata Tingkat Pelayanan Nasabah Pegadaian Syariah Kantor Cabang Langsa Model Antrian Single Channel - Single Phase

\begin{tabular}{|c|c|c|}
\hline Periode Waktu & $\begin{array}{c}\text { Rata - Rata Waktu } \\
\text { Pelayanan }\end{array}$ & $\begin{array}{c}\text { Rata - Rata Tingkat } \\
\text { Pelayanan }\end{array}$ \\
\hline $09.00-10.00$ & 5 & 12 Orang \\
\hline $10.00-11.00$ & & \\
\hline $11.0-12.00$ & & \\
\hline
\end{tabular}

\subsubsection{Uji Kesesuaian}

Pada uji kesesuaian ini dilakukan menggunakan uji Goodness Of Fit untuk menguji data apakah sampel yang diambil berkaitan dengan hipotesis yang menyatakan populasi asal sampel tersebut mengikuti distribusi yang sudah ditetapkan. Menentukan data tingkat kedatangan dan data tingkat pelayanan menggunakan uji Goodness Of Fit pada SPSS 23 dengan menggunakan Kolmogorov Smirnov. Pengujian dilakukan dengan menggunakan Kolmogorov Smirnov untuk membandingkan antara nilai signifikansi dengan nilai a (taraf nyata), sehingga dapat disimpulkan apakah dapat di terima atau di tolak. Berikut merupakan hasil tes distribusi menggunakan SPSS dengan menguji Goodness Of Fit menggunakan Kolmogorov Smirnov.

Tabel 3 : Uji Kolmogorov Smirnov Distribusi Poisson Model Antrian Single Channel Single Phase

\begin{tabular}{|l|c|}
\hline & Kedatangan \\
\hline Kolmogorov Smirnov & 0,427 \\
\hline Asymp Sig. (2-tailed) & 0,993 \\
\hline
\end{tabular}

Tabel 3 Menunjukkan bahwa nilai Sig. adalah 0,993 dan lebih besar dari $\alpha$ (taraf nyata) yaitu 0,05 sehingga hasil pengujian SPSS menunjukkan bahwa data kedatangan berdistribusi Poisson.

$\mathrm{H}_{0}$ : Data kedatangan berdistribusi Poisson

$\mathrm{H}_{1}$ : Data kedatangan tidak berdistribusi Poisson

Tabel 4 : Uji Kolmogorov Smirnov Distribusi Eksponensia/Model Antrian Single Channel Single Phase

\begin{tabular}{|l|c|}
\hline & Pelayanan \\
\hline Kolmogorov Smirnov & 2,761 \\
\hline Asymp Sig. (2-tailed) & 0,000 \\
\hline
\end{tabular}


Tabel 4 Menunjukkan bahwa nilai Sig. adalah 0,000 dan lebih kecil dari a (taraf nyata) yaitu 0,05 sehingga hasil pengujian SPSS menunjukkan bahwa data kedatangan tidak berdistribusi Eksponensial.
$\mathrm{H}_{0}$ : Data pelayanan berdistribusi Eksponensial
$\mathrm{H}_{1}$ : Data pelayanan tidak berdistribusi Eksponensial

Tabel 5 : Uji Kolmogorov Smirnov Distribusi Genera/Model Antrian Single Channel Single Phase

\begin{tabular}{|l|c|}
\hline & Pelayanan \\
\hline Kolmogorov Smirnov & 0,125 \\
\hline Asymp Sig. (2-tailed) & 0,200 \\
\hline
\end{tabular}

Tabel 5 Menunjukkan bahwa nilai Sig. adalah 0,200 dan lebih besar dari a (taraf nyata) yaitu 0,05 sehingga hasil pengujian SPSS menunjukkan bahwa data kedatangan berdistribusi General.
$\mathrm{H}_{0}$ : Data pelayanan berdistribusi General
$\mathrm{H}_{1}$ : Data pelayanan tidak berdistribusi General

Tabel 6 : Hasil kinerja sistem antrian pada Pegadaian Syariah Cabang Langsa dengan model antrian M/G/1 menggunakan Aplikasi POM QM For Windows 5

\begin{tabular}{|c|c|c|c|c|}
\hline $\begin{array}{c}\text { Periode Waktu } \\
\text { (Jam) }\end{array}$ & Parameter & Nilai & Menit & Detik \\
\hline \multirow{5}{*}{$09.00-10.00$} & Average server utilization & 0,67 & & \\
\hline & Average number in the queue $(\mathrm{Lq})$ & 0,67 & & \\
\hline & Average number in the system (Ls) & 1,33 & & \\
\hline & Average time in the queue $(\mathrm{Wq})$ & 0,08 & 5,00 & 300 \\
\hline & Average time in the system (Ws) & 0,17 & 10,00 & 600 \\
\hline \multirow{5}{*}{$10.00-11.00$} & Average server utilization & 0,67 & & \\
\hline & Average number in the queue (Lq) & 0,67 & & \\
\hline & Average number in the system (Ls) & 1,33 & & \\
\hline & Average time in the queue $(\mathrm{Wq})$ & 0,08 & 5,00 & 300 \\
\hline & Average time in the system (Ws) & 0,17 & 10,00 & 600 \\
\hline \multirow{5}{*}{$11.00-12.00$} & Average server utilization & 0,58 & & \\
\hline & Average number in the queue (Lq) & 0,41 & & \\
\hline & Average number in the system (Ls) & 1,00 & & \\
\hline & Average time in the queue $(\mathrm{Wq})$ & 0,06 & 4,00 & 240 \\
\hline & Average time in the system (Ws) & 0,14 & 8,40 & 504 \\
\hline
\end{tabular}


Tabel 6 Merupakan hasil kinerja model sistem antrian Single Channel - Single Phase dimana rata-rata waktu pelayanan adalah 5 menit, rata-rata waktu yang dihabiskan nasabah untuk menunggu dalam antrian $\left(w_{q}\right)$ adalah sekitar 5 menit merupakan waktu terpanjang yang terjadi pada jam 09.00 - 10.00 dan 10.00 - 11.00. Sedangkan untuk waktu rata - rata yang dihabiskan nasabah dalam sistem $\left(\mathrm{w}_{\mathrm{s}}\right.$ ) adalah sekitar 10 menit merupakan waktu terpanjang yang terjadi pada jam $10.00-11.00$

\subsection{Gambar dan Tabel}

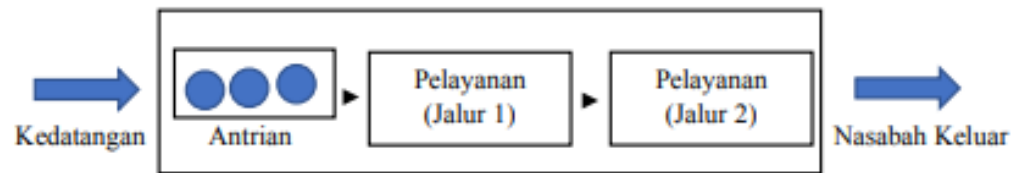

Gambar 2 : Sistem Antrian Pada Pegadaian Syariah Cabang Langsa Model Antrian Single Channel Multi Phase

Gambar 2 di atas menjelaskan bahwa sistem antrian Single Channe/ Multi Phase yaitu terdapat dua atau lebih fasilitas pelayanan yang dilakukan secara berurut (dalam phase - phase) dengan antrian tunggal.

Tabel 7 : Data Rata-Rata Tingkat Kedatangan Nasabah Pegadaian Syariah Kantor Cabang Langsa Model Antrian Single Channel Multi Phase

\begin{tabular}{|c|c|c|}
\hline $\begin{array}{c}\text { Interval Waktu Kedatangan } \\
(\text { Jam })\end{array}$ & $\begin{array}{c}\text { Jumlah Kedatangan } \\
\text { Selama 25 Hari }\end{array}$ & $\begin{array}{c}\text { Rata - Rata } \\
\text { Kedatangan }\end{array}$ \\
\hline $09.00-10.00$ & 182 & 7 Orang \\
\hline $10.00-11.00$ & 225 & 9 Orang \\
\hline $11.00-12.00$ & 150 & 6 Orang \\
\hline
\end{tabular}

Tabel 8 : Data Rata-Rata Tingkat Pelayanan Nasabah Pegadaian Syariah Kantor Cabang Langsa Model Antrian Single Channel Multi Phase

\begin{tabular}{|c|c|c|c|c|}
\hline Periode Waktu & $\begin{array}{c}\text { Rata - Rata } \\
\text { Waktu } \\
\text { Pelayanan 1 }\end{array}$ & $\begin{array}{c}\text { Rata - Rata } \\
\text { Tingkat } \\
\text { Pelayanan }\end{array}$ & $\begin{array}{c}\text { Rata - Rata } \\
\text { Waktu } \\
\text { Pelayanan 2 }\end{array}$ & $\begin{array}{c}\text { Rata - Rata } \\
\text { Tingkat } \\
\text { Pelayanan }\end{array}$ \\
\cline { 1 - 2 } $09.00-10.00$ & 5 & 12 Orang & 6 Menit & 10 Orang \\
\cline { 1 - 1 } $10.00-11.00$ & $11.00-12.00$ & & &
\end{tabular}




\subsubsection{Uji Kesesuaian}

Pada uji kesesuaian ini dilakukan menggunakan uji Goodness Of Fit untuk menguji data apakah sampel yang diambil berkaitan dengan hipotesis yang menyatakan populasi asal sampel tersebut mengikuti distribusi yang sudah ditetapkan. Menentukan data tingkat kedatangan dan data tingkat pelayanan menggunakan uji Goodness Of Fit pada SPSS 23 dengan menggunakan Kolmogorov Smirnov. Pengujian dilakukan dengan menggunakan Kolmogorov Smirnov untuk membandingkan antara nilai signifikansi dengan nilai a (taraf nyata), sehingga dapat disimpulkan apakah dapat di terima atau di tolak. Berikut merupakan hasil tes distribusi menggunakan SPSS dengan menguji Goodness Of Fit menggunakan Kolmogorov Smirnov.

Tabel 9 : Uji Kolmogorov Smirnov Distribusi Poisson Model Antrian Single Channel Multi Phase

\begin{tabular}{|l|c|}
\hline & Kedatangan \\
\hline Kolmogorov Smirnov & 0,463 \\
\hline Asymp Sig. (2-tailed) & 0,983 \\
\hline
\end{tabular}

Tabel 9 Menunjukkan bahwa nilai Sig. adalah 0,983 dan lebih besar dari $\alpha$ (taraf nyata) yaitu 0,05 sehingga hasil pengujian SPSS menunjukkan bahwa data kedatangan berdistribusi Poisson.

$\mathrm{H}_{0}$ : Data kedatangan berdistribusi Poisson

$\mathrm{H}_{1}$ : Data kedatangan tidak berdistribusi Poisson

Tabel 10 : Uji Kolmogorov Smirnov Distribusi Eksponensial Model Antrian Single Channel Single Phase

\begin{tabular}{|l|c|c|}
\hline & Pelayanan 1 & Pelayanan 2 \\
\hline Kolmogorov Smirnov & 2,464 & 2,758 \\
\hline Asymp Sig. (2-tailed) & 0,000 & 0,000 \\
\hline
\end{tabular}

Tabel 10 Menunjukkan bahwa nilai Sig. pada pelayanan 1 dan 2 adalah 0,000 dan lebih kecil dari a (taraf nyata) yaitu 0,05 sehingga hasil pengujian SPSS menunjukkan bahwa data kedatangan tidak berdistribusi Eksponensial.

$\mathrm{H}_{0}$ : Data pelayanan berdistribusi Eksponensial

$\mathrm{H}_{1}$ : Data pelayanan tidak berdistribusi Eksponensial

Tabel 11 : Uji Kolmogorov Smirnov Distribusi General Model Antrian Single Channel Single Phase

\begin{tabular}{|l|c|c|}
\hline & Pelayanan 1 & Pelayanan 2 \\
\hline Kolmogorov Smirnov & 0,154 & 0,122 \\
\hline Asymp Sig. (2-tailed) & 0,131 & 0,200 \\
\hline
\end{tabular}


Tabel 5 Menunjukkan bahwa nilai Sig. pada pelayanan 1 dan 2 adalah 0,131 dan 0,200 lebih besar dari a (taraf nyata) yaitu 0,05 sehingga hasil pengujian SPSS menunjukkan bahwa data kedatangan berdistribusi General.

$$
\begin{aligned}
& \mathrm{H}_{0} \text { : Data pelayanan berdistribusi General } \\
& \mathrm{H}_{1} \text { : Data pelayanan tidak berdistribusi General }
\end{aligned}
$$

Tabel 12 : Hasil kinerja sistem antrian pada Pegadaian Syariah Cabang Langsa dengan model

\begin{tabular}{|c|c|c|c|c|c|c|c|}
\hline $\begin{array}{c}\text { Periode } \\
\text { Waktu (Jam) }\end{array}$ & Parameter & Nilai & Menit & Detik & Nilai & Menit & Detik \\
\hline \multirow{5}{*}{$09.00-10.00$} & $\begin{array}{c}\text { Average server } \\
\text { utilization }\end{array}$ & 0,58 & & & 0,7 & & \\
\hline & $\begin{array}{l}\text { Average number } \\
\text { in the queue }(\mathrm{Lq})\end{array}$ & 0,41 & & & 0,82 & & \\
\hline & $\begin{array}{l}\text { Average number } \\
\text { in the system (Ls) }\end{array}$ & 1,00 & & & 1,52 & & \\
\hline & $\begin{array}{l}\text { Average time in } \\
\text { the queue }(\mathrm{Wq})\end{array}$ & 0,06 & 4,00 & 240 & 0,12 & 7,20 & 432 \\
\hline & $\begin{array}{l}\text { Average time in } \\
\text { the system (Ws) }\end{array}$ & 0,14 & 8,40 & 504 & 0,22 & 13,20 & 792 \\
\hline \multirow{5}{*}{$10.00-11.00$} & $\begin{array}{c}\text { Average server } \\
\text { utilization }\end{array}$ & 0,75 & & & 0,9 & & \\
\hline & $\begin{array}{l}\text { Average number } \\
\text { in the queue }(\mathrm{Lq})\end{array}$ & 1,13 & & & 4,05 & & \\
\hline & $\begin{array}{l}\text { Average number } \\
\text { in the system (Ls) }\end{array}$ & 1,88 & & & 4,95 & & \\
\hline & $\begin{array}{l}\text { Average time in } \\
\text { the queue }(\mathrm{Wq})\end{array}$ & 0,13 & 8,00 & 480 & 0,45 & 27,00 & 1620 \\
\hline & $\begin{array}{l}\text { Average time in } \\
\text { the system (Ws) }\end{array}$ & 0,21 & 13,00 & 780 & 0,55 & 33,00 & 1980 \\
\hline \multirow{4}{*}{$11.00-12.00$} & $\begin{array}{c}\text { Average server } \\
\text { utilization }\end{array}$ & 0,5 & & & 0,6 & & \\
\hline & $\begin{array}{l}\text { Average number } \\
\text { in the queue }(\mathrm{Lq})\end{array}$ & 0,25 & & & 0,45 & & \\
\hline & $\begin{array}{l}\text { Average number } \\
\text { in the system (Ls) }\end{array}$ & 0,75 & & & 1,05 & & \\
\hline & $\begin{array}{l}\text { Average time in } \\
\text { the queue }(\mathrm{Wq})\end{array}$ & 0,04 & 4,00 & 240 & 0,08 & 5,00 & 300 \\
\hline
\end{tabular}
antrian M/G/1 menggunakan Aplikasi POM QM For Windows 5 


\begin{tabular}{|l|c|c|c|c|c|c|c|}
\hline & $\begin{array}{c}\text { Average time in } \\
\text { the system (Ws) }\end{array}$ & 0,13 & 8,00 & 480 & 0,18 & 11,00 & 660 \\
\hline
\end{tabular}

Tabel 12 Merupakan hasil kinerja model sistem antrian Single Channel - Multi Phase dimana rata-rata waktu pelayanan pertama adalah 5 menit dan pelayanan kedua 6 menit, ratarata waktu yang dihabiskan nasabah untuk menunggu dalam antrian $\left(\mathrm{w}_{\mathrm{q}}\right)$ adalah 8 menit pada pelayanan pertama merupakan waktu terpanjang yang terjadi pada jam $10.00-11.00$, dan 27 menit pada pelayanan kedua merupakan waktu terpanjang yang terjadi pada jam $10.00-11.00$ Sedangkan untuk waktu rata - rata yang dihabiskan nasabah dalam sistem ( $\mathrm{w}_{\mathrm{s}}$ ) adalah 13 menit untuk pelayanan pertama terjadi pada jam 10.00 - 11.00 dan 33 menit untuk waktu pelayanan kedua yang terjadi pada jam $10.00-11.00$ merupakan waktu pelayanan terpanjang.

\section{KESIMPULAN}

Terdapat dua model Kinerja sistem antrian yang diterapkan pada Pegadaian Syariah Kantor Cabang Langsa menggunakan model antrian (M/G/1):(FIFO/ / $/ \infty)$ artinya model pelayanan hanya ada satu, distribusi kedatangan poisson dan distribusi pelayanan general/umum. Sedangkan model antrian yang diterapkan satu lagi adalah (M/G/2):(FIFO/œ/œ) artinya model pelayanan terdapat dua, distribusi kedatangan poisson dan distribusi pelayanan generallumum. Jumlah satuan pelayanan waktu adalah first in first out, jumlah nasabah yang boleh masuk tidak berhingga dalam sistem antrian dan ukuran populasi pada sumber masukan yang tidak berhingga. Pada sistem antrian Single Channel - Single Phase Rata - rata waktu yang dihabiskan nasabah untuk menunggu dalam antrian (wq) adalah sekitar 5 menit merupakan waktu terpanjang yang terjadi pada jam 09.00 - 11.00 WIB dan Waktu rata - rata yang dihabiskan nasabah dalam sistem (ws) adalah sekitar 10 menit merupakan waktu terpanjang yang terjadi pada jam 10.00 - 11.00 WIB. sedangkan pada sistem antrian Single Channel - Multi Phase Rata - rata waktu yang dihabiskan nasabah untuk menunggu dalam antrian (wq) adalah 8 menit pada pelayanan pertama merupakan waktu terpanjang yang terjadi pada jam $10.00-11.00 \mathrm{WIB}, 27$ menit pada pelayanan kedua merupakan waktu terpanjang yang terjadi pada jam $10.00-11.00$ WIB. Waktu rata - rata yang dihabiskan nasabah dalam sistem (ws) adalah 13 menit untuk pelayanan pertama terjadi pada jam 10.00 - 11.00 Wib dan 33 menit untuk pelayanan kedua yang terjadi pada jam 10.00 - 11.00 WIB merupakan pelayanan terpanjang. saran dari penelitian ini adalah agar meningkatkan kinerja pelayanan pada model antrian Single Channel - Multi Phase agar lebih cepat dalam menangani permasalahan sehingga nasabah tidak banyak menghabiskan waktu dalam sistem antrian. 


\section{DAFTAR PUSTAKA}

[1]. Faisal, F, Pendekatan Teori Antrian: Kasus Nasabah Bank Pada Pukul 08.00-11.00 Wib di Bank BNI 46 Cabang Bengkulu, Fakultas Matematika dan IImu Pengetahuan Alam Jurusan Matematika, Vol.1, No.2, 2005.

[2]. Amalia, R, Dkk, Pemodelan Sistem Antrian Poli Jantung di RSUD Kota Langsa Menggunakan Struktur Antrian Single Channel - Single Phase, Program Studi Pendidikan Matematika Universitas Samudra, 2018.

[3]. Indrianto, A, Analisis Antrian Pada Pelayanan jasa Gadai Studi Kasus Perum Pegadaian Cabang Condong Catur Yogyakarta, Fakultas Ekonomi Jurusan Manajemen Universitas Sanata Dharma Yogyakarta, Skripsi, 2008.

[4]. Aminah, Si, Analisis Antrian Multi Channel Multi Phase Pada Antrian Pembuatan Surat Izin Mengemudi Dengan Model Antrian (M/M/c):(GD/o/o), Buletin IImiah Mat. Stat. dan Terapannya (Bimaster), Vol. 04, No. 2, 2015.

[5]. Purba, A, Penerapan Sistem Antrian Registrasi Dengan Metode Multi Channel-Multi Phase, Teknik Informatika Universitas Prima Indonesia (UNPRI), Vol. 1, No. 2, 2018.

[6]. Tarigan, F. S, Analisis Sistem Antrian Multi Channel - Multi phase Pada Kantor Badan Penyelenggara Jaminan Sosial (BPJS) Regional I Medan, Fakultas Matematika Universitas Negeri Medan, 2017.

[7]. Ginting, P. L, Analisis Sistem Antrian Dan Optimalisasi Layanan Teller, Fakultas Ekonomika Dan Bisnis Universitas Diponegoro Semarang, Skripsi, 2013.

[8]. Maulana, M. S, Pengembangan Dan Implementasi Aplikasi Antrian Loket Pelayanan Masyarakat Menggunakan Metode Multi Channel - Single Phase, Program Studi Manajemen Informatika, AMIK "BSI Pontianak", Vol. 4, No. 1, 2016.

[9]. Serlina, L, Analisis Sistem Antrian Pelanggan Bank Rakyat Indonesia (BRI) Cabang Bandar Lampung Menggunakan Model Anrian Multi Channel - Single Phase, Fakultas Tarbiyah Dan Keguruan Jurusan Pendidikan Matematika Universitas Islam Negeri Raden Intan Lampung, Skripsi, 2018.

[10]. R. Harahap, S. A, Analisis Sistem Antrian Pelayanan Nasabah Di PT. Bank Negara Indonesia (Persero) TBK Kantor Cabang Utama USU, Saintia Matematika, Vol. 02, No. 03, 2014.

[11]. Sugito, M. A. M, Distribusi Poisson Dan Distribusi Eksponensial Dalam Proses Stokastik, Media Statistik FMIPA UNDIP, Vol. 4, No. 2, 2011. 
[12]. Arwindy, F, Dkk, Analisis Dan Simulasi Sistem Antrian Pada Bank ABC, Saintia Matematika, Vol. 2, No. 2, 2014.

[13]. Maulana, A, Dkk, Analysis Of (M/G/C):(GD/o/\%) Menggunakan Software Lazarus, Program Studi Statistik FMIPA Universitas Mulawarman, Vol. 8, No. 2, 2017

[14]. Mukarrama, F. A, Dkk, Sistem Antrian Single Channel - Multiple Phase Dalam Meningkatkan Pelayanan Pembayaran Pajak Kendaraan Bermotor Di Kantor Sistem Administrasi Manunggal Satu Atap (SAMSAT) Kota Palu, Program Studi Statistika, Fakultas Matematika dan IImu Pengetahuan Alam, Vol. 6, No. 2, 2017.

[15]. Saumi, F, Dkk, Penggunaan Software POM QM V5 Untuk Menganalisis Sistem Antrian, Matematika, Fakultas Teknik, Universitas Samudra, Vol. 1, No. 2, 2018.

[16]. Aulele, S. N, Analisis Sistem Antrian Pada Bank Mandiri Cabang Ambon, Jurusan Matematika, FMIPA UNPATTI, Vol. 8, No. 1, 2014.

[17]. Nurfitria, D, Dkk, Analisis Antrian Dengan Model Single Channe/ single Phase Service Pada Stasiun Pengisian Bahan Bakar Umum (SPBU) I Gusti Nugrahai Palu, Program Studi Matematika, Fakultas Matematika dan Ilmu Pengetahuan Alam, Universitas Tadulako, Vol. 12, No.2, 2016.

[18]. Juanita, Z, Analisis Antrian SPBU 34-13907 Kota Jakarta Timur, Manajemen, Sekolah Tinggi IImu Ekonomi Indonesia, Jakarta, 2020. 